\title{
Analysis of factors involved in brain-death donor processing for face transplantation in Korea: How much time is available from brain death to transplantation?
}

\author{
Jong Won Hong, Soon Won Chung, Sung Jae Ahn, Won Jai Lee, Dae Hyun Lew, Yong Oock Kim \\ Department of Plastic and Reconstructive Surgery, Institute for Human Tissue Restoration, Yonsei University College of Medicine, Seoul, Korea
}

Background Face transplantation has naturally evolved from reconstructive procedures. However, few institutions perform face transplantations, because it is time-consuming and it is necessary to justify non-vital organ transplantation. We investigated the process of organ donation from brain-dead patients and the possibility of incorporating face transplantation into the donation process.

Methods A retrospective review was performed of 1,074 brain-dead patients from January 2015 to December 2016 in Korea. We analyzed the time intervals from admission to brain death decisions (first, second, and final), the causes of brain death, and the state of the transplanted organs.

Results The patient base $(n=1,074)$ was composed of 747 males and 327 females. The average period between admission to the first brain death decision was 8.5 days ( \pm 15.3 ). The average time intervals between the first brain death decision and medical confirmation using electroencephalography and between the first brain death decision and the final determination of brain death were 16 hours 58 minutes ( \pm 14 hours 50 minutes) and 22 hours 57 minutes ( \pm 16 hours 16 minutes), respectively. The most common cause of brain death was cerebral hemorrhage/stroke (42.3\%), followed by hypoxia (30.1\%), and head trauma (25.2\%).

Conclusions When face transplantation is performed, the transplantation team has 22 hours 57 minutes on average to prepare after the first brain death decision. The cause of brain death was head trauma in approximately one-fourth of cases. Although head trauma does not always imply facial trauma, surgeons should be aware that the facial tissue may be compromised in such cases.

Keywords Brain death / Transplantation / Tissue and organ procurement
Correspondence: Jong Won Hong Department of Plastic and Reconstructive Surgery, Institute for Human Tissue Restoration, Yonsei University College of Medicine, 50 Yonsei-ro, Seodaemun-gu, Seoul 03722, Korea

Tel: +82-2-2228-2225

Fax: +82-2-393-6947

E-mail: saturn@yuhs.ac

Received: January 25, $2019 \bullet$ Revised: April 5, $2019 \bullet$ Accepted: July 3, 2019

pISSN: 2234-6163 • elSSN: 2234-6171 • https://doi.org/10.5999/aps.2019.00150 • Arch Plast Surg 2019;46:405-413

We thank Kyoung Ock Jeon, Sun Young Son, and Dong Uk Kim, Department of Transplantation Surgery, Severance Hospital, who are transplantation coordinator for brain death patient data. And we also appreciate Korean Network for Organ Sharing (KONOS) for data sharing.

\section{INTRODUCTION}

As of 2018, 39 cases of face transplantation have been per- formed [1]. The ethical and immunosuppressant-related issues that were brought up in the early period of vascularized composite tissue allotransplantation (VCA) have been addressed.

Copyright (C) 2019 The Korean Society of Plastic and Reconstructive Surgeons

This is an Open Access article distributed under the terms of the Creative Commons Attribution Non-Commercial License (http://creativecommons.org/

licenses/by-nc/4.0/) which permits unrestricted non-commercial use, distribution, and reproduction in any medium, provided the original work is properly cited.

www.e-aps.org 
The results for facial expression capacity and control of rejection have so far been satisfactory [2].

However, facial transplantation is not widely performed because the number of possible recipients is not as high as that of possible vital organ recipients. Moreover, differences exist from country to country in terms of regulations, systems, legal issues, associations, and cultural and social consensus [3-6]. Nevertheless, sufficient common ground exists for facial transplantation to be incorporated into the current organ transplantation system.

When a donor for solid organ transplantation becomes braindead, patient information including medical history, a broad range of immunological testing, and clinical and imaging studies must be confirmed and shared with the recipient hospital. Unlike in cases of solid organ transplantation, the condition of the skin, soft tissue, and bone must be evaluated for facial or hand transplantations. Since the nerves and vascular structures are superficial, unlike internal organs, a previous history of trauma or surgical incisions is important and must be noted. In addition, skin color and tone differs by age, sex, race, and individual variations [7]. Therefore, in cases of face transplantations, the plastic surgery team must directly interact with the brain-dead patient and perform clinical and physical evaluations that are more detailed than those needed for the conventional solid organ transplantation information-sharing system. Additionally, a donor facial restoration in the form of a mask should be prepared before the end of donor procurement. Considering all these steps, there is often not enough time before performing facial transplantations.

We investigated the timing of brain-dead donor processing and factors influencing that process. We also aimed to determine how much time is available to prepare for facial transplantations. To that end, we analyzed the actual time taken in the process from the occurrence of potential brain death events to the final brain death decision.

\section{METHODS}

\section{Organ transplantation organization and the brain death decision-making process}

Organ transplantation is regulated by the Organ Transplantation Act in Korea. The Korean Network for Organ Sharing (KONOS), which is under the supervision of the Ministry of Health and Welfare, manages the organ transplantation process. The enrollment of potential brain-dead patients and the process of matching them to recipient patients is well-regulated by government organizations. When a suspected case of brain death occurs, the hospital reports the case to KONOS after the family agrees to organ donation. Next, the potential brain-dead patient goes through the brain death confirmation process before organ transfer to waiting recipient patients who are also confirmed by KONOS [8]. We submitted the plan for the present study to KONOS and requested data. Prior to sending the data, KONOS excluded personal information. After officially being given the de-identified data, we conducted the analysis described herein.

The final brain death decision must be made before organ procurement. For each donor, the first and second brain death decisions are made at each hospital on the basis of physical examinations. According to the Organ Transplantation Act, the second brain death decision is made at least 6 hours after the first brain death decision for patients above 6 years of age. Then, electroencephalography (EEG) is performed to ensure that the final brain death decision meets medical criteria for brain death. The final brain death decision is made by a specific committee with the task of performing a comprehensive examination to ascertain brain death. The actual surgical procedure for organ procurement is performed after the final confirmation of brain death (Fig. 1) [9-11].

\section{Study design}

We analyzed 1,074 brain-dead donors from January 2015 to December 2016 in Korea. All patients were enrolled in the organ transplantation program. All of the data were officially received from KONOS. However, the analyzed factors differed from those in the KONOS annual report. Since the fundamental purpose of this study was to investigate the process that would be utilized for face transplantations in adults, we targeted adults at least 19 years of age who were not considered minors under Korean law, yielding a total of 1,004 brain-death donors. We analyzed the time intervals of the clinically relevant points from admission to the final brain death decision. We also analyzed patients' age, blood type, and reasons for brain death.

We investigated each time interval involving the first brain death decision, the second brain death decision, the EEG decision, and the final brain death decision. Time was analyzed from admission for the medical event that caused brain death. Since donor information is officially shared after the first brain death decision, we regarded the first brain death decision as an important milestone. The second brain death decision can be made at least 6 hours after the first brain death decision by law. Since the brain death decision process and preparation for the procurement operation are performed quickly after the second brain death decision, the second brain death decision is also an important time point. The EEG decision and final decision by the committee for determining brain death play a meaningful role in terms of medical and social confirmation of brain death. The final brain death decision is made by a committee composed of 


\section{Fig. 1. The brain death decision process in Korea}

Two brain death decisions are made on the basis of physical examinations. Electroencephalography (EEG) is performed to confirm brain death. The final brain death decision is rendered by the committee for determining brain death at each hospital. Donations for transplantations can then be performed. The entire procedure is performed under the Organ Transplantation Act.

Committee Donation

(Final brain death decision)

EEG brain death decision

First brain death decision

Second brain death decision
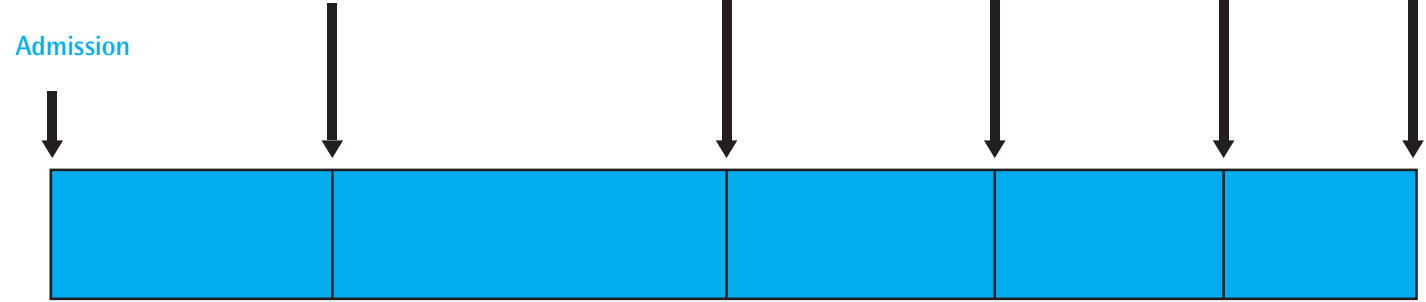

\section{Fig 2. Age distribution of brain death donors}

Overall, there were 2.3 times more male donors than female donors. The most common age for brain death was $51-60$ years for males and 41-50 years for females. Those age groups accounted for $53.6 \%$ of all brain death donors.

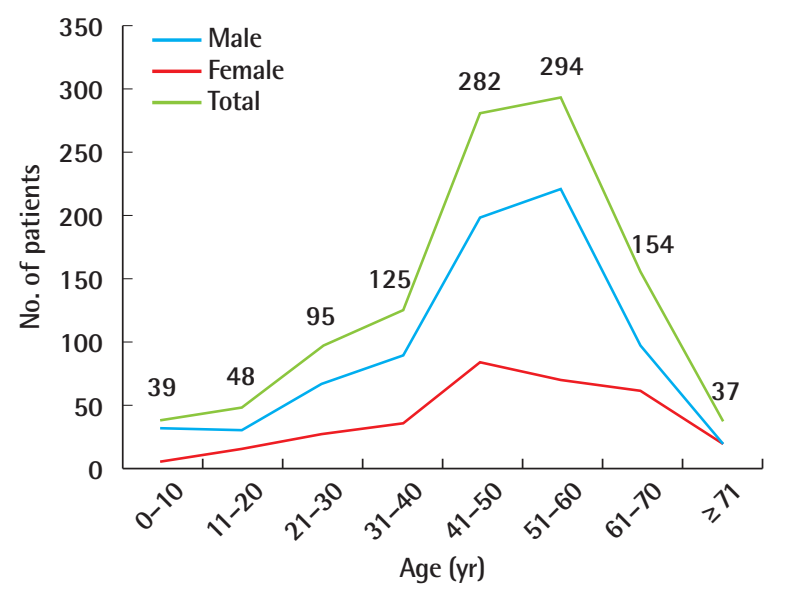

medical staff, lawyers, hospital staff, clergy, and socially wellknown people, taking social consensus and ethical considerations into account.

\section{Statistical analysis}

Continuous variables are summarized as mean values ( \pm standard deviation). Data analyses were performed using SPSS version 13.0 (SPSS Inc., Chicago, IL, USA).
Fig. 3. ABO blood type distribution among brain-dead donors

The $A B$ type accounted for the smallest proportion of donors, at $12 \%$. The distribution of blood types in this study is similar to that of the Korean general population.

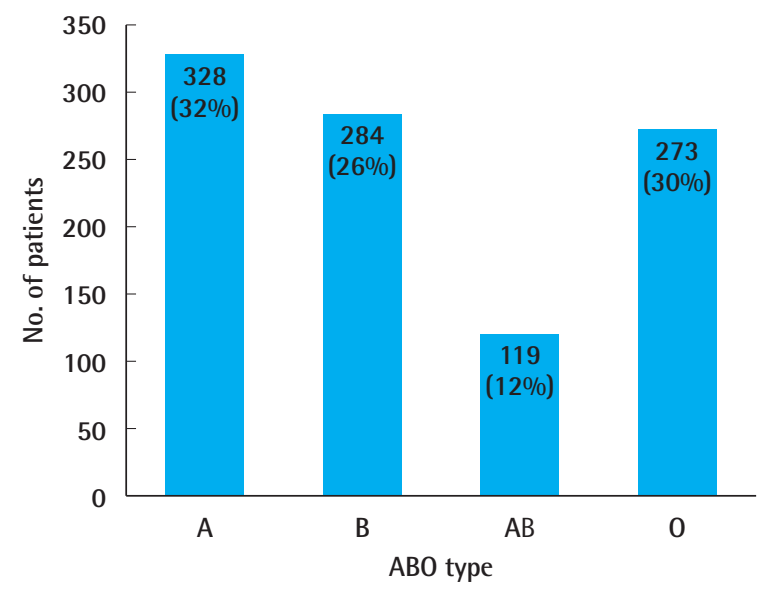

\section{RESULTS}

We analyzed all patients $(n=1,074)$ by age. The greatest number of females and males were in their 40s and 50s, respectively. The majority of brain-dead donors were in their 50s, and males were 2.3 times as common as females. The number of donors in their $40 \mathrm{~s}$ and $50 \mathrm{~s}$ accounted for $53.6 \%$ of all the donors (Fig. 2). Organ-specific transplantations with an $\mathrm{ABO}$ blood type mis- 
Table 1. Analysis of the timing of the process from admission to the final brain death decision

\begin{tabular}{|lcc|}
\hline Brain death decision process & Time interval (mean \pm SD) & Range \\
\hline Admission to first brain death decision & $6.6 \pm 5.5$ day & $0-30$ day \\
First to second brain death decision & $11 \mathrm{hr} 2 \mathrm{~min} \pm 6 \mathrm{hr} 48 \mathrm{~min}$ & $6 \mathrm{hr} 5 \mathrm{~min}-3$ day $19 \mathrm{hr} 35 \mathrm{~min}$ \\
Second brain death decision to EEG & $6 \mathrm{hr} \pm 11 \mathrm{hr} 50 \mathrm{~min}$ & $30 \mathrm{~min}-6$ day $1 \mathrm{hr} 50 \mathrm{~min}$ \\
EEG to final brain death decision & $6 \mathrm{hr} 2 \mathrm{~min} \pm 8 \mathrm{hr} 9 \mathrm{~min}$ & $5 \mathrm{~min}-2$ day $23 \mathrm{hr}$ \\
First brain death decision to EEG & $16 \mathrm{hr} 3 \mathrm{~min} \pm 13 \mathrm{hr} 35 \mathrm{~min}$ & $6 \mathrm{hr} 35 \mathrm{~min}-6$ day $9 \mathrm{hr} 45 \mathrm{~min}$ \\
First to final brain death decision & $22 \mathrm{hr} 2 \mathrm{~min} \pm 15 \mathrm{hr} 11 \mathrm{~min}$ & $6 \mathrm{hr} 49 \mathrm{~min}-6$ day $12 \mathrm{hr} 35 \mathrm{~min}$ \\
Second to final brain death decision & $10 \mathrm{hr} 59 \mathrm{~min} \pm 13 \mathrm{hr} 58 \mathrm{~min}$ & $39 \mathrm{~min}-6$ day $4 \mathrm{hr} 40 \mathrm{~min}$ \\
\hline EEG, electroencephalography. & & \\
\hline
\end{tabular}

\section{Fig. 4. Time intervals until EEG brain death}

The electroencephalography (EEG) decision represents the medical determination of brain death. The first brain death decision is important for practical surgical preparation. The time from admission to the first brain death decision took an average of 6.6 days. The time from the first brain death decision to the EEG decision took an average of 16 hours and 3 minutes.

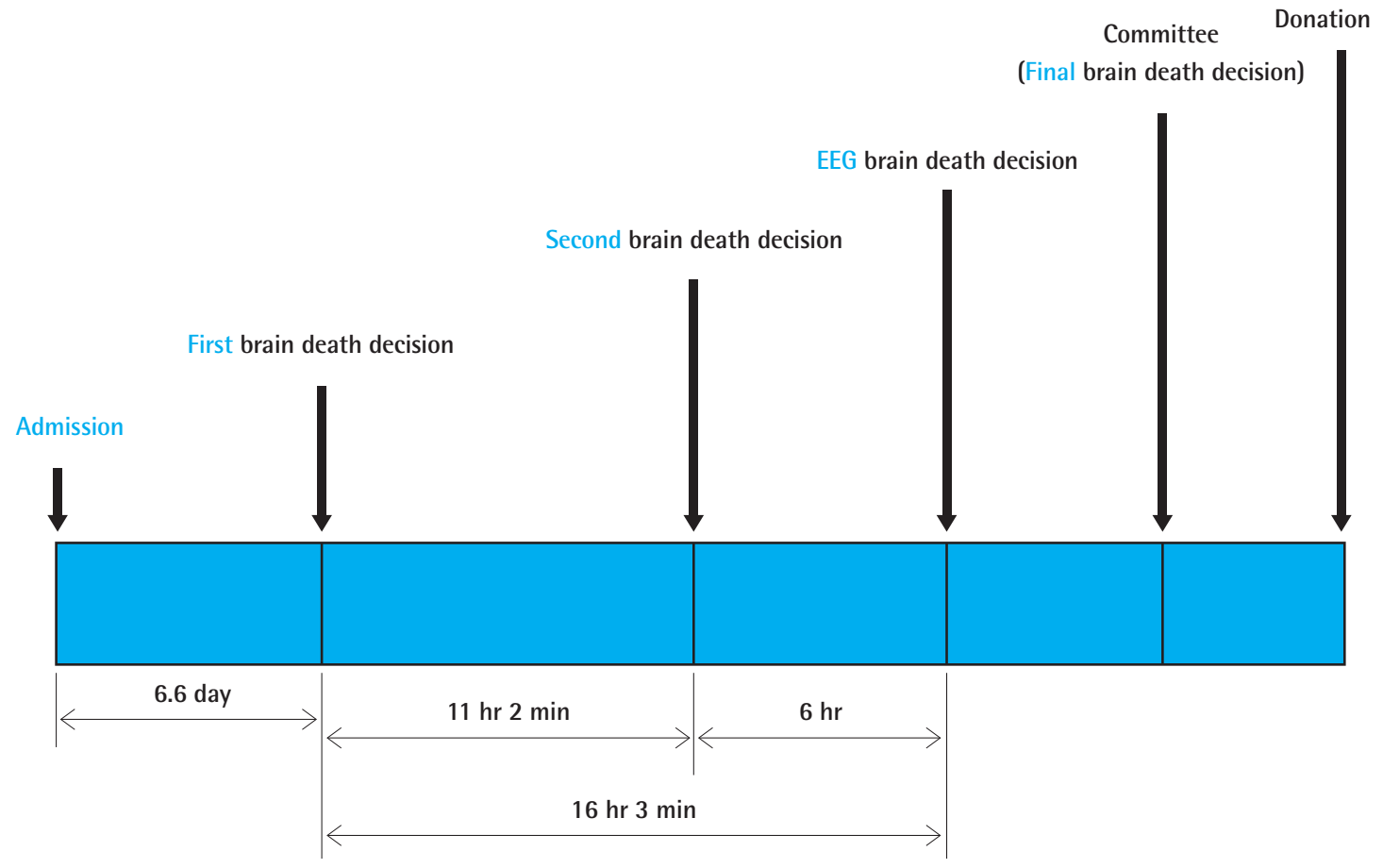

match can be performed, but for face transplantations, the $\mathrm{ABO}$ blood type should be matched to reduce the possibility of rejection. Blood type analysis was performed for donors who were at least 19 years of age and considered legal adults. The $\mathrm{AB}$ type was present in $12 \%$ of the donors, while the $\mathrm{A}, \mathrm{B}$, and $\mathrm{O}$ blood types made up $32 \%, 26 \%$, and $30 \%$ of the patient population in this study, respectively. This distribution was similar to the blood type distribution of the Korean general population (Fig. 3) [12].

The time interval between each point in the brain death process is shown in Table 1. An average of 6.6 days passed from admission to the first brain death decision. Not all patients become brain-dead immediately after admission. In addition, the families of potentially brain-dead patients did not always agree to organ donation immediately. Therefore, the timeframe from admission to the first brain death decision was relatively long. The longest time interval from admission to the first brain death decision was 30 days. The second brain death decision can be made starting 6 hours after the first brain death decision under the Organ Transplantation Act. However, the average time interval was 11 hours and 2 minutes. The average time from the second brain death decision to EEG confirmation was 6 hours, even though EEG is part of the confirmation process. That means that EEGs were not performed urgently. The time from 


\section{Fig. 5. Time intervals until final brain death}

The time from the electroencephalography (EEG) decision to the committee decision was, on average, 6 hours and 2 minutes, while an average of 22 hours and 2 minutes was needed from the first brain death decision to the committee decision.

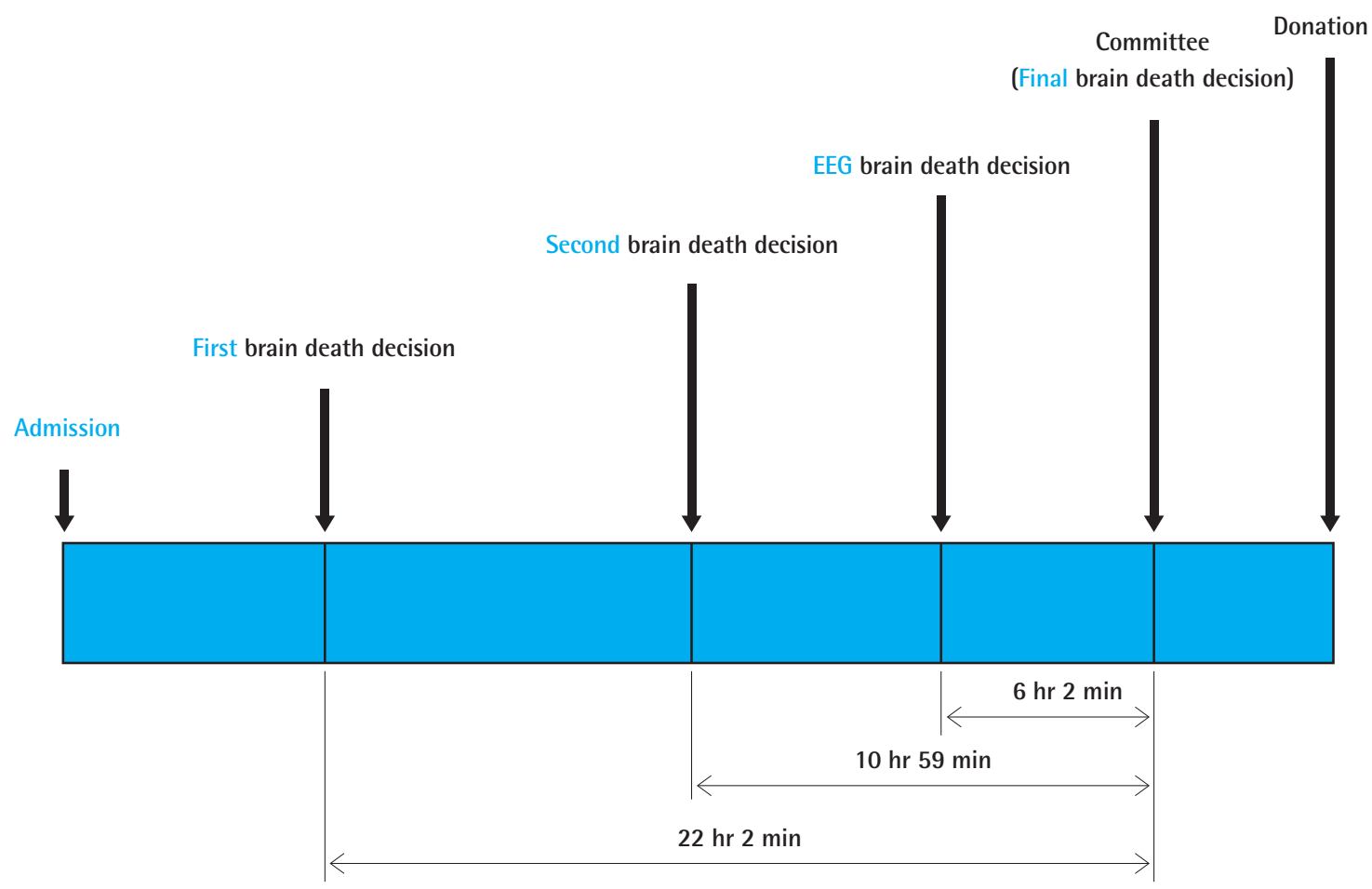

\section{Fig. 6. Causes of brain death}

The most common cause of brain death was cerebrovascular disease/stroke. The second and third most common causes were brain hypoxia and head trauma, respectively.

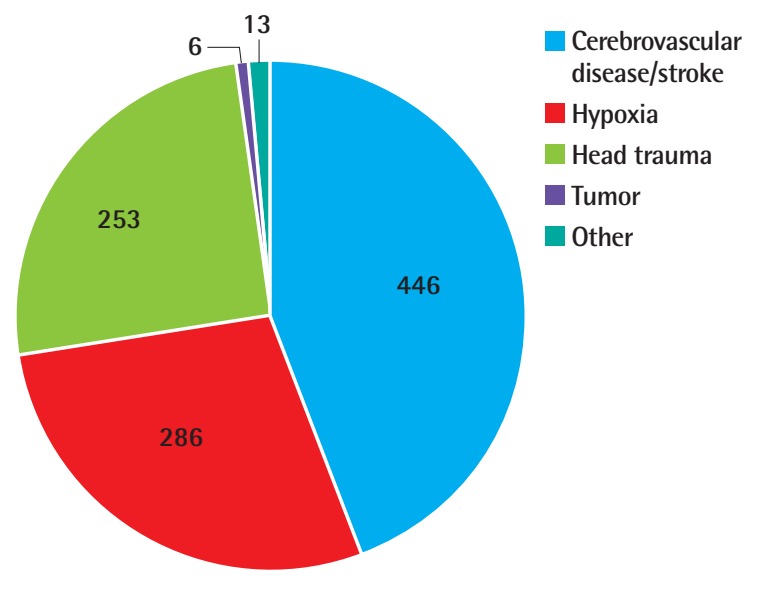

the EEG brain death confirmation to committee confirmation took an average of 6 hours and 2 minutes, even though brain death had already been confirmed medically.

It took an average of 16 hours and 3 minutes from the first brain death decision to the EEG for the medical confirmation of

\begin{tabular}{|c|c|c|c|}
\hline Cause & No. & $\begin{array}{l}\text { Proportion of cases } \\
\text { of brain death due to } \\
\text { hypoxia }(n=286)\end{array}$ & $\begin{array}{l}\text { Proportion of all } \\
\text { cases of brain death } \\
(n=1,004)\end{array}$ \\
\hline Asphyxia & 155 & 54.2 & 15.4 \\
\hline Cardiac arrest & 92 & 32.2 & 9.2 \\
\hline Drowning & 6 & 2.1 & 0.6 \\
\hline Seizure & 5 & 1.7 & 0.5 \\
\hline Other & 28 & 9.8 & 2.8 \\
\hline Total & 286 & 100.0 & 28.5 \\
\hline
\end{tabular}

brain death. However, actual organ transplantation is only possible after the decision of the committee. Therefore, when analyzed based on the decision of the committee for determining brain death decision, an average of 22 hours and 2 minutes passed from the first brain death decision to EEG confirmation. An average of 10 hours and 59 minutes elapsed from the second brain death decision to the final brain death decision (Figs. 4, 5).

Unlike solid organ transplantations, knowledge of a previous surgical or trauma history to the face is very important in VCA, especially for cases of brain death due to head trauma, in which facial trauma is likely to occur. As all head trauma patients experience facial trauma, we thought that it would be meaningful to 
analyze the reason for brain death to allow for an indirect estimate of the cases in which facial trauma would be likely. The most common reason for brain death was cerebrovascular disease/stroke, which accounted for $44.4 \%$ of brain deaths; meanwhile, $28.5 \%$ were attributed to brain hypoxia and $25.2 \%$ to head trauma (Fig. 6).

Unlike other causes of brain death, brain hypoxia is a category that contains many previous diagnoses. We analyzed $286 \mathrm{hy}-$ poxic brain deaths, and most resulted from asphyxia (54.2\%). The second leading cause of hypoxic brain death was cardiac arrest (32.2\%) (Table 2). Fifty-three cases of hypoxic brain death resulted from suicide by hanging.

\section{DISCUSSION}

Organ transplants are emergent procedures, as distinct from elective surgery. The recipient must be ready to enter the hospital at any time since it is impossible to predict when a donor will appear. If a surgeon has a donor, the surgeon must be able to perform the relevant surgery at a moment's notice. Previously performed face transplantation procedures have taken much longer than conventional reconstructive procedures [13]. Donor-recipient suitability must be determined according to factors that are never considered for traditional transplants, such as soft tissue condition, skin color, skin tone, hair, and age, in addition to immunological factors. This information must be verified directly by the operators themselves.

Due to these novel requirements for information, it takes a long time to prepare the donor before surgery. Knowing how much time is required before any transplantation operation can be helpful not only for preoperative preparations, but also for management of the transplantation team, with goals including efficient allocation of time and maintenance of stamina.

VCA has steadily become more common worldwide, with increases observed in the number of surgical procedures, operative fields, nations, and durations from the first modern hand transplantation in Lyon, France in 1998 [14]. Hand transplantations have been performed in more than 80 cases, while facial transplantations have been performed in 39 cases $[1,14]$. Most of the cases were performed in the United States and Europe, but some have been performed in other nations, such as Turkey and Taiwan [14-16]. The results of VCA, especially for face and hand transplantations, are very inspiring so far, with great improvements observed in patients' lives. The immunosuppressant drugs that were once major issues at the beginning of VCA have become more similar to the regimens used for solid organ transplantation. In addition, studies have been conducted to identify ways to induce immune tolerance in clinical settings
[17]. In Korea, the first upper limb transplantation procedure was performed in February 2017. Hand function and immunosuppression have been well maintained in that patient 2 years. As a result, the Organ Transplantation Act was revised in 2017, with Korea moving towards institutional improvements and a greater social consensus $[18,19]$.

However, there are many issues that remain to be solved in order to perform VCA. Even if a procedure is possible on the medical level, numerous institutional, social, and ethical issues must be resolved in conjunction with other medical fields [2022]. Therefore, it is rational to incorporate VCA into the current transplantation system. This has been a common approach to VCA at other medical institutions internationally. However, plastic surgeons are not generally familiar with the transplantation system, and solid organ transplantation surgeons are not usually familiar with the reconstructive field. Plastic surgeons have little knowledge of organ procurement and transplantation procedures in brain-dead donors. The entire management of the process from its preoperative stages (including recipient and donor selection) to its postoperative stages (including immune suppression) is very important to the success of VCA $[23,24]$.

All nations manage donors and recipients fairly and ethically in a way that is deeply grounded in ethical principles through organizations such as KONOS in Korea, the United Network for Organ Sharing in the United States, and the Japan Organ Transplant Network in Japan. In those organizations, information on brain-dead donors is shared with the recipient medical team. Face transplantations are uncommon in the organ transplantation field. The shared information about the donor must contain information about the face, including facial movements, soft tissue conditions, skin color, and hair, in addition to the immunological information that is already shared. Therefore, it is difficult to rely on traditional brain-dead donor organizations that are not used to facial transplantations. The reconstructive transplantation team that will perform the face transplantation must directly check and evaluate the brain death donor patient. A facial mask for the donor patient must also be prepared for facial restoration for their funeral before the end of the donor procurement operation. These processes are very different from solid organ transplantations, which only require shared information about solid organs.

The actual time interval from the preparation of the braindead patient to the actual start of the face transplantation surgery must be known. To predict how many brain-dead donors can be candidates for face transplantation donation, we analyzed their age, blood type, and causes of brain death, which are basic data that differ from country to country. The purpose of this study was to investigate the time interval from the identification 
of a potential brain-dead donor to brain death confirmation with reference to Korean demographics.

We investigated 2 years of data from KONOS, from January 2015 to December 2016. Age and sex are meaningful for face transplantations because skin color, tone, and character usually differ according to age and sex. Recently, $\mathrm{ABO}$ blood mismatch organ transplantations have become available for several conditions. Nonetheless, it remains the case that every antigen should be matched in order to prevent rejection in VCA, based on its short history. Since the ABO blood type must be matched for face transplantations, we analyzed the blood types of the braindead donors. The distribution of the ABO blood types of the patients in this study is similar to the distribution in the Korean general population.

We consider the first brain death decision to be a very important time point, as it is when information about the brain-dead donor begins to be shared. EEG decisions and committee decisions were also considered to be important time points for final medical brain death decisions and comprehensive decisions. Clinically, preparations for organ transplantations begin after the first brain death decision. The recipient is hospitalized and prepared for surgery. The next step after the second brain death decision involves the confirmation process. Therefore, the second brain death decision is also a meaningful time point.

In the time interval analysis, standard deviation and range were quite wide in each category. Therefore, it was not meaningful to compare each group using the t-test. Since vascular events in the central nervous system are commonly caused by stroke or hemorrhage, head trauma, cardiovascular ischemia, and sudden heart attacks, patients' conditions may be unstable and variable. In addition, organ donations are difficult decisions for families and medical staff because of extra-medical issues. These reasons explain the wide range of the data. Admissions of possible braindead donors are challenging to standardize. As a result, the time interval from admission to the first brain death decision varied considerably.

Summarizing various results and their causes, we believe that the interval from the first brain death decision to the EEG decision about medical brain death is the ideal time for preoperative preparations to check the condition of the donor face and to decide whether face transplantation is possible. Since face transplantations can begin after the decision of the committee, the time from the first brain death decision to the final brain death decision by the committee is a bonus in terms of preparation for surgery. These intervals were, on average, 16 hours and $3 \mathrm{~min}-$ utes and 22 hours and 2 minutes, respectively. The standard deviation and range must be taken into account, as various factors may cause an increase or reduction in the actual time compared to the average time.

Since the majority of brain deaths are due to traffic accidents, we analyzed the causes of brain death involving the possibility of facial trauma. Head trauma accounted for $28.5 \%$ of brain deaths. Although head trauma does not perfectly coincide with facial trauma, it is possible to use head trauma statistics as a rough estimate of the number of patients from whom this possibility must be considered. Furthermore, $44.4 \%$ and $25.2 \%$ of donor brain deaths resulted from cerebrovascular disease/stroke and brain hypoxia, respectively. Hypoxia was very common in the data from KONOS. Therefore, the mechanism of death in the hypoxia cases was analyzed. Hypoxia due to cardiac arrest was found in 92 (15.4\%) of the 1,004 total brain deaths. However, the number of suicides was 53 in this study. This result did not include suicides by carbon monoxide poisoning or drowning. In the future, it is necessary to discuss whether donors who have committed suicide can be used for face transplantations.

We previously analyzed the time interval of the brain death decision process for 648 brain death donors between January 2011 to August 2012. In that time period, the time from the first brain death decision to the EEG decision was, on average, 14 hours and 35 minutes, while the interval from the first brain death decision to the decision of the committee took an average of 18 hours and 11 minutes. In a recent study, the time intervals had increased [25], but no meaningful difference was seen because there was at least a 4-year gap between the two study groups. The standard deviations were also too large for the difference to be statistically significant. In a previous study, the organs used for transplantations were analyzed. Hearts and/or lungs were procured in $30.1 \%$ of donors from January 2011 to August 2012. The possibility of interference between face transplantation and heart and lung transplantation teams must be discussed.

It is not straightforward for the new area of VCA to join the existing traditional solid organ transplantation field. Each field must have an understanding of the other. In the first upper limb transplantation performed in Korea in February 2017, the organ procurement procedure took only 15 minutes, but there were many issues related to donor procurement. More factors must be taken into account for face transplantations than for hand transplantations. Face transplantations were rejected three times by the Korean government from 2010 to 2017 as a new technology for insurance coverage in Korea. Fortunately, existing organ transplantation specialists and institutions have become familiar with the procedure and have tried to develop VCA through the revised Organ Transplantation Act. There are fewer candidates for face transplantations in Korea than in other countries where the procedure has already been performed. In addition, the so- 
ciocultural background of organ donation is different across countries. Nonetheless, considering the medical outlook in Korea and the reconstructive level of plastic surgery, the possibility of face transplantation should be considered when the opportunity arises.

Plastic surgeons must understand the overall transplantation process. Specific factors must be investigated for face transplantations, in addition to those which are routinely conducted for other transplantation fields. Based on this study and previous research, plastic surgeons should continue to improve their knowledge of transplantation procedures, increase their level of collaboration with transplantation specialists, and make suggestions based on evidence and opinions for the revision of institutional and legal policies.

\section{NOTES}

\section{Conflict of interest}

No potential conflict of interest relevant to this article was reported.

\section{Ethical approval}

The study was approved by the Institutional Review Board of Severance Hospital (IRB No. 4-2019-0336) and performed in accordance with the principles of the Declaration of Helsinki. Written informed consents were obtained.

\section{Author contribution}

Conceptualization: Hong JW. Data curation: Hong JW. Formal analysis: Hong JW, Chung SW, Ahn SJ. Methodology: Hong JW, Chung SW, Ahn SJ. Project administration: Hong JW, Chung SW. Visualization: Lee WJ, Lew DH, Kim YO. Writingreview \& editing: Hong JW, Chung SW, Ahn SJ. Approval of final manuscript: all authors.

\section{ORCID}

Jong Won Hong https://orcid.org/0000-0002-7762-0940 Soon Won Chung https://orcid.org/0000-0002-4761-3942 Sung Jae Ahn https://orcid.org/0000-0002-0324-0451 Won Jai Lee https://orcid.org/0000-0003-3056-0503 Dae Hyun Lew https://orcid.org/0000-0002-2625-5664 Yong Oock Kim https://orcid.org/0000-0002-3756-4809

\section{REFERENCES}

1. Lindford AJ, Makisalo H, Jalanko H, et al. The Helsinki approach to face transplantation. J Plast Reconstr Aesthet Surg 2019;72:173-80.
2. Sosin M, Rodriguez ED. The face transplantation update: 2016. Plast Reconstr Surg 2016;137:1841-50.

3. Kiwanuka H, Bueno EM, Diaz-Siso JR, et al. Evolution of ethical debate on face transplantation. Plast Reconstr Surg 2013;132:1558-68.

4. Nguyen LL, Naunheim MR, Hevelone ND, et al. Cost analysis of conventional face reconstruction versus face transplantation for large tissue defects. Plast Reconstr Surg 2015; 135:260-7.

5. Siemionow M. Face transplantation: a leading surgeon's perspective. Transplant Proc 2011;43:2850-2.

6. Pomahac B. Establishing a composite tissue allotransplantation program.J Reconstr Microsurg 2012;28:3-6.

7. Knobloch K, Rennekampff HO, Vogt PM. Face as an organ: a political dimension in the European Union. Ann Plast Surg 2009;62:335.

8. Min SI, Ha J. Recent progresses in organ donation and transplantation in Korea. Transplantation 2015;99:2431-3.

9. Morrissey PE, Monaco AP. Donation after circulatory death: current practices, ongoing challenges, and potential improvements. Transplantation 2014;97:258-64.

10. Jericho BG. Organ donation after circulatory death: ethical issues and international practices. Anesth Analg 2019;128: 280-5.

11. Waters CE, French G, Burt M. Difficulty in brainstem death testing in the presence of high spinal cord injury. $\mathrm{Br} \mathrm{J} \mathrm{An-}$ aesth 2004;92:760-4.

12. Korean Statistical Information Service (KOSIS). Statistics of blood donation by blood type [Internet]. Daejeon: KOSIS; c2019 [cited 2019 Jan 7]. Available from: http://kosis.kr/ statHtml/statHtml.do?orgId=445\&tblId=DT_445001_006\& vw_cd=MT_ZTITLE\&list_id=D1_445001\&seqNo=\&lang mode $=$ ko\&language $=$ kor\&obj_var_id $=\& i t m \_i d=\&$ conn path=MT_ZTITLE.

13. Devauchelle B, Badet L, Lengele B, et al. First human face allograft: early report. Lancet 2006;368:203-9.

14. MacKay BJ, Nacke E, Posner M. Hand transplantation--a review. Bull Hosp Jt Dis (2013) 2014;72:76-88.

15. Kuo YR, Chen CC, Chen YC, et al. The first hand allotransplantation in Taiwan: a report at 9 months. Ann Plast Surg 2016;77:S12-5.

16. Guo S, Han Y, Zhang X, et al. Human facial allotransplantation: a 2-year follow-up study. Lancet 2008;372:631-8.

17. Ozkan O, Ertosun MG, Ozkan O. Technical, immunological, and ethical similarities and differences between vascularized composite allotransplantation and solid organ transplantation in current practice. Transplant Proc 2018;50:377582. 
18. Kim YJ. The first hand transplant in Korea... then, face off? The Dong'A Ilbo. 2017 Feb 21. Available from: http://news. donga.com/3/all/20170220/82962288/1.

19. Enforcement decree of the Internal Organs, etc. Transplantation Act of 2008, Pub. No. 29230 (2018 Oct 16).

20. Morris P, Bradley A, Doyal L, et al. Face transplantation: a review of the technical, immunological, psychological and clinical issues with recommendations for good practice. Transplantation 2007;83:109-28.

21. Clarke A, Butler PE. Patient selection for facial transplantation II: psychological considerations. Int J Surg 2004;2:1167.

22. Johnson SE, Corsten MJ. Facial transplantation in a new era: what are the ethical implications? Curr Opin Otolaryngol Head Neck Surg 2009; 17:274-8.

23. Siemionow M, Gordon CR. Overview of guidelines for establishing a face transplant program: a work in progress. Am J Transplant 2010;10:1290-6.

24. Pomahac B, Diaz-Siso JR, Bueno EM. Evolution of indications for facial transplantation. J Plast Reconstr Aesthet Surg 2011;64:1410-6.

25. Hong JW. Analysis of the processing time from the brain death to transplantation for the face transplantation. Proceedings of the 9th Korea Japan Transplantation Forum; 2012 Oct 19-20; Incheon, Korea. Abstract No. 12B-093. 